\title{
Recent Advances in IR and UV/VIS Spectroscopic Characterization of the $C_{76}$ and $C_{84}$ Isomers of $D_{2}$ Symmetry
}

\author{
Tamara Jovanović, ${ }^{1}$ Đuro Koruga, ${ }^{1}$ and Branimir Jovančićevićc ${ }^{2}$ \\ ${ }^{1}$ Department of Biomedical Engineering, Faculty of Mechanical Engineering, University of Belgrade, \\ Kraljice Marije 16, 11120 Belgrade, Serbia \\ ${ }^{2}$ Department of Applied Chemistry, Faculty of Chemistry, University of Belgrade, Studentski Trg 12-16, 11000 Belgrade, Serbia
}

Correspondence should be addressed to Tamara Jovanović; tjovanovic@mas.bg.ac.rs

Received 23 July 2014; Revised 13 November 2014; Accepted 13 November 2014; Published 15 December 2014

Academic Editor: William W. Yu

Copyright (C) 2014 Tamara Jovanović et al. This is an open access article distributed under the Creative Commons Attribution License, which permits unrestricted use, distribution, and reproduction in any medium, provided the original work is properly cited.

\begin{abstract}
The stable isomers of the higher fullerenes $\mathrm{C}_{76}$ and $\mathrm{C}_{84}$ with $\mathrm{D}_{2}$ symmetry as well as the basic fullerenes $\mathrm{C}_{60}$ and $\mathrm{C}_{70}$ were isolated from carbon soot and characterized by the new and advanced methods, techniques, and processes. The validity of several semiempirical, ab initio, and DFT theoretical calculations in predicting the general pattern of IR absorption and the vibrational frequencies, as well as the molecular electronic structure of the $\mathrm{C}_{76}$ and $\mathrm{C}_{84}$ isomers of $\mathrm{D}_{2}$ symmetry, is confirmed, based on recent experimental results. An excellent correlation was found between the previously reported theoretical data and the recently obtained experimental results for these molecules over the relevant spectral range for the identification of fullerenes. These results indicate that there are no errors in the calculations in the significant spectral regions, the assumptions that were based on previous comparisons with partial experimental results. Isolated fullerenes are important for their applications in electronic and optical devices, solar cells, optical limiting, sensors, polymers, nanophotonic materials, diagnostic and therapeutic agents, health and environment protection, and so forth.
\end{abstract}

\section{Introduction}

There is only one stable isomer of the higher fullerene $\mathrm{C}_{76}$, as well as of the basic fullerenes, characterized by $\mathrm{D}_{2}$, icosahedral (Ih) and $\mathrm{D}_{5 \mathrm{~h}}$ symmetry, isolated pentagons, and an electronic closed shall structure [1]. From the 24 possible isomers of $\mathrm{C}_{84}$ obeying the isolated pentagon rule $[2,3]$, the two most stable, most abundant, and almost isoenergetic structures are those with $\mathrm{D}_{2}$ and $\mathrm{D}_{2 \mathrm{~d}}$ symmetry [4-12], found in a $2: 1$ ratio [13-15].

Some of the numerous possible vibrational modes of the higher fullerenes $\mathrm{C}_{76}[16,17], \mathrm{C}_{84}[5,6]$, and its $\mathrm{D}_{2}(\mathrm{IV})[18-20]$ and $\mathrm{D}_{2 \mathrm{~d}}(\mathrm{II})$ isomers $[19,21]$ were detailed in previous studies.

In this research, a series of unique, new, and dominant IR absorption maxima of the isolated $\mathrm{C}_{76}$ and the most abundant, stable $\mathrm{C}_{84}$ isomer of $\mathrm{D}_{2}$ symmetry is registered and confirmed in the spectral region relevant for the identification of fullerenes, from ca. 450 to $1650 \mathrm{~cm}^{-1}$. The general pattern of the obtained spectra and all the observed absorption bands of the chromatographically isolated samples of the stable $\mathrm{C}_{76}$ and $\mathrm{C}_{84}$ isomers with $\mathrm{D}_{2}$ symmetry from the several different original, advanced separation processes [22-28] are in excellent agreement with the semiempirical, ab initio, and density functional theory (DFT) theoretical calculations for these molecules [5-12, 29, 30] over the mentioned relevant region. It should be noted that some low frequencies can exist below the observational limit of $400 \mathrm{~cm}^{-1}$.

These results have not been previously reported. Some discrepancies between the previous experimental data [1619] and the aforementioned theoretical calculations [5-12, 29, 30] appeared in the significant spectral regions.

Quantum chemical force field for $\pi$ electrons theoretical (QCFF/PI) calculations yielded a set of the vibrational frequencies for the stable $\mathrm{C}_{76}$ isomer of $\mathrm{D}_{2}$ symmetry [29]. The IR vibrational properties of $\mathrm{C}_{76}$ were also studied using the high-level ab initio B3LYP DFT with the TZVP basis set [30].

The IR vibrational spectra of the two most abundant and most stable, major $\mathrm{C}_{84}$ isomers, the $\mathrm{D}_{2}: 22$ and $\mathrm{D}_{2 \mathrm{~d}}$ :23 isomers, 
were previously theoretically studied using the semiempirical PM3, AM1, MNDO [5-8], QCFF/PI [9], and tight-binding (TB) potential calculations [10]. Vibrational properties of the $\mathrm{D}_{2}, \mathrm{D}_{2 \mathrm{~d}}$, and $\mathrm{C}_{2}$ isomers of $\mathrm{C}_{84}$ were determined by ab initio Hartree Fock (HF) calculations with the STO-3G, 3-21G, and D95V basis sets [11]. The IR vibrational properties of the two major $\mathrm{C}_{84}$ isomers were also studied using the B3LYP DFT with the basis sets as large as $6-31 G^{*}[12]$.

These calculations were already shown to be successful in predicting the overall absorption pattern and the vibrational frequencies, as well as the molecular structures of the basic fullerenes $C_{60}$ and $C_{70}$ [31-35]. Excellent agreement with the experimental data was observed [23, 24, 36-38].

IR spectra of the chromatographically isolated $\mathrm{C}_{76}-\mathrm{D}_{2}$ and $\mathrm{C}_{84}-\mathrm{D}_{2}: 22$ isomers were recorded over the entire relevant region from 400 to $2000 \mathrm{~cm}^{-1}$, by the $\mathrm{KBr}$ disk technique. Characterization of the obtained $\mathrm{C}_{76}$ and $\mathrm{C}_{84}$ fractions from the previous separation processes was performed using different IR techniques, in different spectral regions [5, 6, 16-21].

In the previous articles, the UV/VIS absorption of the higher fullerenes $\mathrm{C}_{76}$ and $\mathrm{C}_{84}$ and its $\mathrm{D}_{2}(\mathrm{IV})$ and $\mathrm{D}_{2 \mathrm{~d}}(\mathrm{II})$ isomers was recorded in different spectral regions. Their solutions in different solvents, of different concentrations, were used [14, 39-47].

In this study, the UV/VIS absorption of the chromatographically purified $\mathrm{C}_{76}$ and $\mathrm{C}_{84}$ isomers of $\mathrm{D}_{2}$ symmetry is registered over the entire relevant region from 200 to $900 \mathrm{~nm}$. A series of their unique, new, and dominant UV absorption maxima are registered and confirmed in the most significant spectral region from 200 to $400 \mathrm{~nm}$, where fullerenes intensively absorb. Solutions of these fullerenes in hexane of determined concentrations were used. It should be mentioned that the region from 200 to $300 \mathrm{~nm}$ has not been previously presented for $\mathrm{C}_{84}$ and its isomers under any experimental conditions. Complete appearance of their electronic absorption spectra and all the observed absorption bands [22-28] correlates well with the previous semiempirical QCFF/PI, TB, and DFT theoretical predictions of the molecular electronic structure and the optical absorption of these molecules that behave as electron deficient arenes [4851]. Their overall absorption also correlates well with the experimentally obtained photoemission spectra (PES) of $\mathrm{C}_{76}$ and $\mathrm{C}_{84}$ [49-51].

It is important to mention that fullerenes $\mathrm{C}_{60}$ and $\mathrm{C}_{70}$ were recently found in space around various astrophysical objects [52], such as certain planetary [53] and protoplanetary nebulae [54] and in other space environments ranging from postasymptotic giant branch stars [55], to young stellar objects [56], to reflection nebulae [57], and to certain RCoronae Borealis stars [58]. It is expected that also higher fullerenes, such as $\mathrm{C}_{76}$ and $\mathrm{C}_{84}$ and their stable isomers with $\mathrm{D}_{2}$ symmetry, can be found in space.

The obtained original spectra of the isolated stable $\mathrm{C}_{76}$ and $\mathrm{C}_{84}$ isomers, measured at room temperature in this study, as well as their comparison with the recent spectra of $\mathrm{C}_{76}$ and $\mathrm{C}_{84}$ (mixture of isomers) at temperatures between $-180^{\circ} \mathrm{C}$ and $+250^{\circ} \mathrm{C}$ [52], are very significant for better understanding of IR and UV/VIS optical absorption properties of these higher fullerenes and for their identification either in natural resources in space and on Earth or in artificially synthesized carbon soots.

\section{Experimental Methods}

In the first phase of this research, $\mathrm{C}_{60}, \mathrm{C}_{70}$, and the higher fullerenes, mainly $\mathrm{C}_{76}$ and $\mathrm{C}_{84}$, were Soxhlet extracted with a series of different and previously unapplied solvents or combinations of solvents from the samples of carbon soot, produced by electric arc (MER Corporation, Tucson, AZ, USA). Solvents used were $n$-heptane, toluene, chlorobenzene, $p$-xylene, xylenes, and pyridine, as well as the successive use of toluene and chlorobenzene, and $p$-xylene and pyridine. The extractions were performed until the complete disappearance of color in the Soxhlet extraction thimble. The yields and the compositions of all the extracts were determined by the spectroscopic and chromatographic methods. The procedures for increases of fullerenes yields, as well as for additional selective extraction of higher order fullerenes, were found [22-28, 36-38].

In the second phase, $\mathrm{C}_{60}, \mathrm{C}_{70}$, and the higher fullerenes $\mathrm{C}_{76}$ and $\mathrm{C}_{84}$ from the obtained soot extracts were chromatographically separated on the activated $\mathrm{Al}_{2} \mathrm{O}_{3}$ columns by the new and improved methods [22-28]. The elution was performed continuously with the several different original, defined gradients of solvents: from pure hexane or $5 \%$ toluene in hexane to pure toluene, at ambient conditions. The main advancement, in comparison to previous methods under pressure $[13-19,39-45]$, is the isolation of the purified stable isomers of the higher fullerenes $\mathrm{C}_{76}$ and $\mathrm{C}_{84}$ (the only stable $\mathrm{C}_{76}-\mathrm{D}_{2}$ isomer and the most abundant, stable $\mathrm{C}_{84}$ isomer of $\mathrm{D}_{2}$ symmetry, the $\mathrm{C}_{84}-\mathrm{D}_{2}: 22$ isomer), successively after the basic fullerenes, in one phase of each of the processes, under atmospheric pressure and smaller flow of $1.5 \mathrm{~mL} / \mathrm{min}$, in increased milligrams yields. The other advantages of the developed methods are the use of significantly smaller amounts of the initial materials, including fullerene extracts $(10 \mathrm{mg})$, finely granulated $\mathrm{Al}_{2} \mathrm{O}_{3}(50 \mathrm{~g})$, activated for $2 \mathrm{~h}$ at $105^{\circ} \mathrm{C}$, and eluent (1.5 to $\left.1.75 \mathrm{~L}\right)$ per chromatographic separation, as well as less expensive laboratory equipment. The entire material and energy expense and the time spent on the purification processes were decreased. The environment pollution was also decreased, using smaller amounts of less toxic solvents [22-28].

Before separation, each sample of the extract (ca. $10 \mathrm{mg}$ ) was dissolved in hexane and toluene (few $\mathrm{mL}$ ), dispersed onto silica ( $1 \mathrm{~g}$ ), which adsorbed the solvent producing gelatinous mass, and finally put onto top of the new alumina column.

Purification of higher fullerenes under pressure, on a preparative scale, either by flash chromatography or by HPLC, generally required larger amounts of the initial materials and repeated chromatographies, and the fullerenes were obtained in smaller yields [14, 39-43].

Characterization of the chromatographically purified fullerene fractions, as well as of the obtained fullerenes soot extracts, was performed using determined techniques of IR and UV/VIS spectroscopy that have not been presented previously for the higher fullerenes [22-28, 36-38]. 
In this paper, the IR spectra of the chromatographically isolated samples of the $\mathrm{C}_{76}$ and $\mathrm{C}_{84}$ isomers of $\mathrm{D}_{2}$ symmetry were measured by a Nicolet FT-IR 6700 spectrometer Thermo Scientific, by the $\mathrm{KBr}$ disk technique, at room temperature, $23^{\circ} \mathrm{C}$, over the entire relevant region from 400 to $2000 \mathrm{~cm}^{-1}$.

The UV/VIS spectra of the chromatographically purified samples of the $\mathrm{C}_{76}$ and $\mathrm{C}_{84}$ isomers of $\mathrm{D}_{2}$ symmetry were recorded on GBC Cintra 40 spectrophotometer, in the region from 200 to $900 \mathrm{~nm}$. Diluted solutions of fullerenes in hexane, concentrations $10^{-3}$ to $10^{-4} \mathrm{~mol} / \mathrm{dm}^{-3}$, were used.

The UV/VIS spectra of the chromatographically purified samples of the $\mathrm{C}_{76}$ and $\mathrm{C}_{84}$ isomers of $\mathrm{D}_{2}$ symmetry were also recorded on a Perkin-Elmer Lambda 5 spectrophotometer, from 200 to $900 \mathrm{~nm}$, using both diluted solutions of fullerenes in hexane, concentrations $10^{-3}$ to $10^{-4} \mathrm{~mol} / \mathrm{dm}^{-3}$, and much diluted solutions of fullerenes in hexane to complete discoloring, for comparison.

In the previous articles, the IR and UV/VIS absorption of the obtained samples of the higher fullerenes $\mathrm{C}_{76}, \mathrm{C}_{84}$, and its $\mathrm{D}_{2}(\mathrm{IV})$ and $\mathrm{D}_{2 \mathrm{~d}}(\mathrm{II})$ isomers were recorded in different spectral regions, using different techniques $[5,6,14,16-21$, 39-47].

\section{Results and Discussion}

The main advancement in spectroscopic characterization of the higher fullerenes $\mathrm{C}_{76}$ and $\mathrm{C}_{84}$ in this research [22-28], in comparison to previously obtained experimental results $[5,6,16-21]$, is the observation of the unique, new, and the main, dominant absorption maxima of the isolated stable $\mathrm{C}_{76}$ and $\mathrm{C}_{84}$ isomers of $\mathrm{D}_{2}$ symmetry in the spectral regions where they intensively absorb, in excellent agreement with the semiempirical, ab initio, and DFT theoretical calculations for these molecules [5-12, 29, 30].

The achieved agreement between our experimental results [22-27] and the aforementioned theoretical predictions $[29,30]$ is better in comparison to previous characterizations of $\mathrm{C}_{76}$ samples from other separation processes, by other IR techniques $[16,17]$.

Whereas there is a good correlation between our experimental results [22-27] and the theoretical predictions [29, $30]$, in the previous experimentally obtained IR spectra of the $\mathrm{C}_{76}$ samples [16,17], some discrepancies of the general pattern and vibrational frequencies with the theoretical predictions $[29,30]$ appear in the central significant part of the spectrum, from ca. 800 to $1200 \mathrm{~cm}^{-1}$.

In the first, partial IR spectrum of $\mathrm{C}_{76}$ [16], some disagreements of absorption bands with the theoretical calculations $[29,30]$ occur in the mentioned region, as well as from ca. 1500 to $1600 \mathrm{~cm}^{-1}$, of up to $40-60 \mathrm{~cm}^{-1}[16,29]$.

The next IR measurement [17] was not in agreement with the mentioned first published spectrum of $\mathrm{C}_{76}$, suggesting that the previous measurement was carried out with an impure sample $[16,17]$. In this study, the absorption bands were not registered from ca. 800 to $1000 \mathrm{~cm}^{-1}$. In the remaining part of the spectrum [17], a larger number of $\mathrm{C}_{76}$ features were observed and also some discrepancies with the theoretical calculations $[29,30]$ in the region around
1020 to $1030 \mathrm{~cm}^{-1}$, as large as $26 \mathrm{~cm}^{-1}[17,29]$. The observed IR features of the higher fullerene $\mathrm{C}_{76}$ from this separation process were tentatively rather assigned to a subset of fundamental vibrations, although there was presumption that some of these features were weaker overtone or combination bands [17], which our results also confirm.

There is a general agreement between the IR absorption bands of $\mathrm{C}_{76}$ observed previously and those observed in this work. In several cases, smaller shifts are observed. However, new, characteristic, and the main, dominant absorption bands not reported in previous works $[16,17]$ were registered in the central significant part of the region relevant for the identification of fullerenes, from ca. 800 to $1200 \mathrm{~cm}^{-1}$, as well as in the region from ca. 1530 to $1740 \mathrm{~cm}^{-1}$.

In Table 1 are reported the IR absorption bands of the chromatographically purified $\mathrm{C}_{76}$ samples as measured in this work at $23^{\circ} \mathrm{C}$ in comparison with the recent data at different temperatures, as well as with the theoretical calculations by the QCFF/PI method [29].

The original experimentally obtained IR spectrum of the chromatographically isolated $\mathrm{C}_{76}-\mathrm{D}_{2}$ sample is presented in Figure 1 (Table 1, first IR).

In this paper, the main, most intense, sharp, well resolved absorption maxima of the higher fullerene $\mathrm{C}_{76}$ were observed at 967,1082 , and $1187 \mathrm{~cm}^{-1}$. Weak neighboring features at $1025,1057,1122$, and $1162 \mathrm{~cm}^{-1}$ correspond to $\mathrm{C}_{76}$. In the recent work [52], a group of four close $\mathrm{C}_{76}$ intense absorption bands were found at 1175, 1102, and 1086 and the most intense at $1030 \mathrm{~cm}^{-1}$, with the neighboring feature at $961 \mathrm{~cm}^{-1}$, appearing in the form of one strong, broad absorption band. Some of these bands were reported with weak intensity in previous works [16, 17], such as features at 1031 and $1175 \mathrm{~cm}^{-1}$ [17].

Characteristic, sharp bands unique to the higher fullerenes $\mathrm{C}_{76}$ were observed in the first relevant part of our spectrum at 892 and $823 \mathrm{~cm}^{-1}$, with the neighboring absorption at $789 \mathrm{~cm}^{-1}$. Pronounced $\mathrm{C}_{76}$ absorption bands also appear at $705 \mathrm{~cm}^{-1}$, with the shoulders at 729 and $743 \mathrm{~cm}^{-1}$, at $603 \mathrm{~cm}^{-1}$ next to absorption at $646 \mathrm{~cm}^{-1}$, and at $533 \mathrm{~cm}^{-1}$. The three most intense absorption bands in the first relevant part of the recent spectrum [52] were observed at 709 and 654 and the main band at $526 \mathrm{~cm}^{-1}$. Their neighboring features appear at 743,608 , and $550 \mathrm{~cm}^{-1}$. Several other neighboring bands are listed in Table 1. Corresponding bands from the previous report were found with some shifts at 693,628 , and $538 \mathrm{~cm}^{-1}$ [17].

In the second relevant part of our spectrum, the most intense, strong absorption band appears at $1461 \mathrm{~cm}^{-1}$ and the next pronounced intense band at $1386 \mathrm{~cm}^{-1}$, with the neighboring feature at $1398 \mathrm{~cm}^{-1}$. Intense band was found at $1438 \mathrm{~cm}^{-1}$ in the recent spectrum, followed by the features at 1393 and $1383 \mathrm{~cm}^{-1}$ [52]. It appears at $1438 \mathrm{~cm}^{-1}$, with the neighboring bands at 1461 and $1466 \mathrm{~cm}^{-1}$ in the previous report [17]. Sharp $C_{76}$ feature observed at $1312 \mathrm{~cm}^{-1}$ in our spectrum, with the next bands at 1276 and $1248 \mathrm{~cm}^{-1}$, was found at $1315 \mathrm{~cm}^{-1}$ recently at $45^{\circ} \mathrm{C}$. The neighboring band was observed at $1288 \mathrm{~cm}^{-1}$ at $-178^{\circ} \mathrm{C}$ [52]. Band at $1493 \mathrm{~cm}^{-1}$ was found at $1498 \mathrm{~cm}^{-1}$ in the recent spectrum [52] and at $1513 \mathrm{~cm}^{-1}$ in the previous work [17]. Pronounced bands were 
TABLE 1: Experimental and theoretically calculated absorption bands of $\mathrm{C}_{76}$ between 400 and $1770 \mathrm{~cm}^{-1}$.

\begin{tabular}{|c|c|c|c|c|c|c|}
\hline \multirow{3}{*}{$\begin{array}{l}\text { Calculated } \\
\text { Orlandi et al. } \\
\text { Absorption bands } \\
\left(\mathrm{cm}^{-1}\right)\end{array}$} & \multicolumn{6}{|c|}{ Experimental } \\
\hline & \multicolumn{3}{|c|}{ This work } & \multicolumn{3}{|c|}{ Cataldo et al. ${ }^{\mathrm{b}}$} \\
\hline & $\begin{array}{c}\text { IR1 } \\
\left(\mathrm{cm}^{-1}\right)\end{array}$ & $\begin{array}{c}\text { IR2 } \\
\left(\mathrm{cm}^{-1}\right)\end{array}$ & $\begin{array}{c}\text { IR3 } \\
\left(\mathrm{cm}^{-1}\right)\end{array}$ & $\begin{array}{l}-178^{\circ} \mathrm{C} \\
\left(\mathrm{cm}^{-1}\right) \\
\end{array}$ & $\begin{array}{l}+45^{\circ} \mathrm{C} \\
\left(\mathrm{cm}^{-1}\right)\end{array}$ & $\begin{array}{l}+250^{\circ} \mathrm{C} \\
\left(\mathrm{cm}^{-1}\right)\end{array}$ \\
\hline & 405 & & & 409 & 409 & \\
\hline & & 426 & 429 & 420 & 420 & 420 \\
\hline & 436 & & & 444 & & 440 \\
\hline 457 & & 456 & & & & \\
\hline 460 & 460 & 462 & 462 & & & 461 \\
\hline 477 & & & 476 & 477 & 477 & 476 \\
\hline \multirow[t]{2}{*}{488} & 487 & 484 & & & & \\
\hline & & & 494 & 491 & 491 & 494 \\
\hline 513 & 507 & & & & & 505 \\
\hline 534 & 533 & 538 & & & & \\
\hline 543 & 539 & & 539 & & & \\
\hline 547 & & & & 549 & 550 & 550 \\
\hline \multirow[t]{2}{*}{555} & 555 & & & & & \\
\hline & & & & 571 & 572 & 571 \\
\hline 581 & & & 581 & & 588 & \\
\hline 596 & 603 & 605 & 605 & & 608 & 607 \\
\hline 632 & & & & & & 629 \\
\hline 652 & 646 & 647 & 648 & 650 & 654 & 652 \\
\hline 662 & 661 & 665 & 664 & & 668 & 669 \\
\hline 684 & 682 & & & & & \\
\hline 707 & 705 & 703 & 704 & & & \\
\hline 710 & & & & 710 & 709 & 710 \\
\hline 730 & 729 & & & & & \\
\hline 746 & 743 & 742 & 740 & 744 & 743 & 742 \\
\hline 760 & & & & 763 & & 763 \\
\hline 770 & & & 767 & & 765 & \\
\hline 787 & 789 & 792 & 796 & 790 & 791 & 791 \\
\hline 810 & & & & 805 & 806 & 804 \\
\hline 823 & 823 & 823 & 821 & & & \\
\hline 825 & & & & 824 & 825 & 825 \\
\hline 841 & & & & 848 & 847 & 847 \\
\hline 895 & 892 & 893 & 892 & & & \\
\hline \multirow[t]{2}{*}{971} & 967 & 967 & 968 & 963 & 971 & 963 \\
\hline & 1024 & & & & 1024 & 1017 \\
\hline 1043 & 1033 & 1029 & 1030 & 1032 & & \\
\hline 1046 & & 1046 & & & & \\
\hline \multirow[t]{2}{*}{1058} & 1056 & & 1057 & & & 1061 \\
\hline & 1067 & & & 1065 & 1066 & \\
\hline 1079 & 1082 & 1082 & 1082 & & & 1086 \\
\hline 1100 & 1098 & & 1101 & 1102 & 1102 & \\
\hline 1124 & 1122 & 1122 & 1122 & 1124 & & \\
\hline 1165 & 1162 & 1160 & & & 1168 & \\
\hline 1171 & & & & 1171 & 1175 & \\
\hline 1189 & 1187 & 1187 & 1185 & & & \\
\hline 1204 & 1209 & 1206 & 1211 & & & \\
\hline 1243 & 1248 & 1248 & 1248 & & & \\
\hline
\end{tabular}

TABLE 1: Continued.

\begin{tabular}{|c|c|c|c|c|c|c|}
\hline \multirow{3}{*}{$\begin{array}{l}\text { Calculated } \\
\text { Orlandi et al. } \\
\text { Absorption bands } \\
\left(\mathrm{cm}^{-1}\right)\end{array}$} & \multicolumn{6}{|c|}{ Experimental } \\
\hline & \multicolumn{3}{|c|}{ This work } & \multicolumn{3}{|c|}{ Cataldo et al. ${ }^{\mathrm{b}}$} \\
\hline & $\begin{array}{c}\text { IR1 } \\
\left(\mathrm{cm}^{-1}\right)\end{array}$ & $\begin{array}{c}\text { IR2 } \\
\left(\mathrm{cm}^{-1}\right)\end{array}$ & $\begin{array}{c}\text { IR3 } \\
\left(\mathrm{cm}^{-1}\right)\end{array}$ & $\begin{array}{l}-178^{\circ} \mathrm{C} \\
\left(\mathrm{cm}^{-1}\right)\end{array}$ & $\begin{array}{l}+45^{\circ} \mathrm{C} \\
\left(\mathrm{cm}^{-1}\right)\end{array}$ & $\begin{array}{l}+250^{\circ} \mathrm{C} \\
\left(\mathrm{cm}^{-1}\right)\end{array}$ \\
\hline 1256 & & & 1263 & & & 1260 \\
\hline 1270 & 1276 & 1273 & & & 1270 & \\
\hline 1294 & 1291 & & & 1288 & & \\
\hline 1312 & 1312 & 1312 & 1311 & 1317 & 1315 & 1312 \\
\hline 1327 & 1339 & & & & & 1339 \\
\hline 1369 & 1364 & 1364 & 1363 & & & 1373 \\
\hline 1388 & 1386 & 1386 & 1385 & 1386 & 1383 & 1386 \\
\hline 1402 & 1398 & 1397 & 1400 & 1395 & 1393 & 1394 \\
\hline 1434 & & & & 1438 & 1438 & 1435 \\
\hline 1464 & 1461 & 1462 & 1460 & & & \\
\hline 1489 & 1493 & 1494 & 1493 & 1491 & 1498 & 1488 \\
\hline 1529 & 1533 & & & & & \\
\hline 1549 & & 1541 & 1542 & & & \\
\hline 1552 & 1552 & & & & & \\
\hline 1556 & & & 1558 & & & \\
\hline 1580 & 1580 & 1582 & 1576 & 1580 & 1580 & 1577 \\
\hline 1607 & & 1605 & & 1601 & 1598 & 1597 \\
\hline 1635 & 1633 & 1635 & 1631 & & & \\
\hline \multirow[t]{5}{*}{1650} & & 1654 & 1653 & & & \\
\hline & 1681 & 1684 & & 1684 & 1688 & 1698 \\
\hline & 1713 & & 1711 & & & \\
\hline & 1734 & 1735 & 1735 & 1718 & 1721 & 1730 \\
\hline & & 1773 & 1774 & & & \\
\hline
\end{tabular}

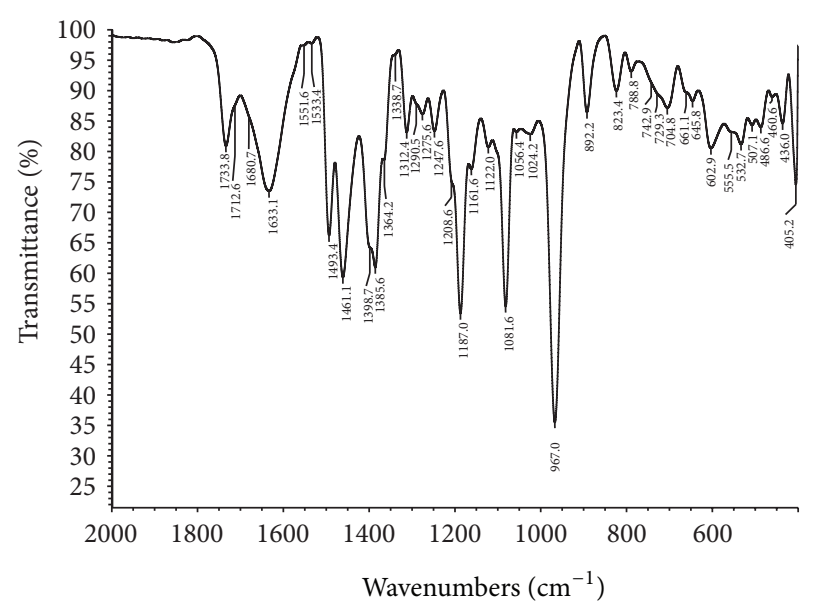

FIGURE 1: The IR spectrum of the chromatographically purified $\mathrm{C}_{76}-\mathrm{D}_{2}$ sample.

also observed in this work at 1735 and $1631 \mathrm{~cm}^{-1}$, with the shoulders at 1580 and $1681 \mathrm{~cm}^{-1}$. The most intense maximum in the recent spectrum was registered at $1688 \mathrm{~cm}^{-1}$, with the next intense band at $1721 \mathrm{~cm}^{-1}$ and the neighboring band at $1598 \mathrm{~cm}^{-1}$, in addition to the band at $1580 \mathrm{~cm}^{-1}$ [52] which 
was detected only with Raman spectroscopy in the previous work [17].

Concerning the dependence of the $\mathrm{C}_{76}$ infrared bands with temperature, some smaller band shifts were observed in our spectrum at $23^{\circ} \mathrm{C}$ in comparison to recent spectra at various temperatures [52]. There is observed a remarkable change of the intensity of certain characteristic infrared bands, depending on temperature.

No important and evident band shifts as a function of temperatures were observed in the mentioned recent spectra as a function of temperature. Their main characteristics and the overall absorptions are similar. However, the intensity of certain infrared bands of $\mathrm{C}_{76}$ is remarkably sensitive to temperature. For example, the band at $1317 \mathrm{~cm}^{-1}$ is sharp at $-178^{\circ} \mathrm{C}$ [52], and still in our spectrum at room temperature, registered at $1312 \mathrm{~cm}^{-1}$, and becomes less intense at $+45^{\circ} \mathrm{C}$ and weak at $+250^{\circ} \mathrm{C}$. Another example is the group of bands comprised between 1288 and $1032 \mathrm{~cm}^{-1}$ which are well defined and separated at $-178^{\circ} \mathrm{C}$ [52] and also in our spectrum seen at 1276 and $1248 \mathrm{~cm}^{-1}$, but appear much less intense at $+250^{\circ} \mathrm{C}$. The IR spectrum of $\mathrm{C}_{78}$ that was also presented in the recent work has different properties [52].

It is important to mention that the general pattern of our $\mathrm{C}_{76}-\mathrm{D}_{2}$ spectrum and all of the experimentally observed IR absorption bands over the spectral region relevant for the identification of fullerenes are in excellent agreement with the theoretical calculations for the only stable $\mathrm{C}_{76}$ isomer of $\mathrm{D}_{2}$ symmetry, by the semiempirical QCFF/PI method [29], as well as by the most recent ab initio DFT [30].

The overall configuration of absorption of our experimentally obtained FT-IR( $\mathrm{KBr})$ spectra of the chromatographically isolated samples of the neutral solid $\mathrm{C}_{76}$ [22-28] correlates well with the next obtained, most recent infrared multiphoton electron detachment (IR-MPED) spectrum of the unsolvated gas-phase dianion $\mathrm{C}_{76}{ }^{2-}$, as well as with the adequate most recent B3LYP/TZVP DFT calculations [30].

The obtained generally good correlation between our recent results for the neutral $\mathrm{C}_{76}[22-28]$ and the most recent IR spectrum of $\mathrm{C}_{76}{ }^{2-}$ [30] provides the significant experimental evidence that the dianionic molecule retains its overall symmetry (i.e., $\mathrm{D}_{2}$ point group) with ${ }^{1} \mathrm{~A}_{1}$ ground state with respect to the neutral cage. This statement was previously based on comparison of the experimental $\mathrm{C}_{76}{ }^{2-}$ IR spectrum with the DFT calculations [30]. Spectral shifts of characteristic $\mathrm{C}_{76}{ }^{2-}$ tangential modes, as well as some changes of their intensity [30], observed relative to the neutral $\mathrm{C}_{76}$ cage [22-28, 30], were shown to originate from the excess charge density on the fullerene cage that leads to some specific changes of bond lengths [30].

The presented results in this study indicate that the previous semiempirical QCFF/PI [29], as well as the recent ab initio DFT theoretical calculations [30], provides an overall excellent prediction of the IR spectrum and vibrational frequencies of the higher fullerene $\mathrm{C}_{76}$. A one to one assignment is achieved over the entire relevant spectral region for fullerenes. Only in a few cases is the accuracy not enough to permit a one to one assignment, as when two IR bands are separated by a small frequency interval. Their assignment can be supported by considering the calculated frequencies by DFT [30] in addition to the QCFF/PI frequencies [29] and conversely.

On the basis of the previous theoretical calculations for the higher fullerene $\mathrm{C}_{84}$, two most abundant stable $\mathrm{D}_{2}: 22$ and $\mathrm{D}_{2 \mathrm{~d}}: 23$ isomers [5-12], a series of characteristic absorption bands is predicted to occur around $780 \mathrm{~cm}^{-1}$ (from ca. 700 to $840 \mathrm{~cm}^{-1}$ ), followed by the bands around 630 and $475 \mathrm{~cm}^{-1}$. Some minor bands should also appear between ca. 585 and $520 \mathrm{~cm}^{-1}$, in the first relevant part of the spectrum (ca. 450 to $850 \mathrm{~cm}^{-1}$ ). Pronounced and dominant, most intense absorption bands are predicted to occur in the second relevant part (ca. 1050 to $1650 \mathrm{~cm}^{-1}$ ), around $1600 \mathrm{~cm}^{-1}$ and a group between ca. 1125 and $1390 \mathrm{~cm}^{-1}$, including the main band. A cluster of minor bands should appear at higher wave numbers than the main band.

The two calculated $\mathrm{D}_{2}-\mathrm{C}_{84}$ and $\mathrm{D}_{2 \mathrm{~d}}-\mathrm{C}_{84}$ spectra resemble each other, the difference being that the $\mathrm{D}_{2}$ isomer shows more IR active lines due to splitting of the lines from the higher symmetry $\mathrm{D}_{2 \mathrm{~d}}$ isomer. However, these splitting are much too small and they could not be resolved in the first published IR spectrum of $\mathrm{C}_{84}$, between 500 and $2000 \mathrm{~cm}^{-1}$ [5], or in the previous infrared resonance enhanced multiphoton ionization (IR-REMPI) spectrum of $\mathrm{C}_{84}$, presented between 450 and $1600 \mathrm{~cm}^{-1}$ [6]. This spectrum consisted of only three absorption bands at 748,632 , and $475 \mathrm{~cm}^{-1}$ in the first part, followed by a series of partially unresolved peaks, ranging from ca. 1050 to $1600 \mathrm{~cm}^{-1}$.

Our experimentally obtained IR spectra of the chromatographically purified samples of the most abundant, stable $\mathrm{C}_{84}$ isomer of $\mathrm{D}_{2}$ symmetry, $\mathrm{C}_{84}-\mathrm{D}_{2}: 22$ [23-28], have much better resolution of absorption bands, in comparison to the first published IR absorption spectrum of $\mathrm{C}_{84}$ [5] and to the previous IR-REMPI spectrum [6], as well as to the IR spectra of the $\mathrm{C}_{84}-\mathrm{D}_{2 \mathrm{~d}}$ samples, presented in the regions from 484 to $1631 \mathrm{~cm}^{-1}$ [19], as well as from 50 to $500 \mathrm{~cm}^{-1}$ and 500 to $800 \mathrm{~cm}^{-1}$ [21]. They agree and look more similar to the theoretically calculated spectrum of the $\mathrm{D}_{2}: 22$ isomer [5-12], which shows more IR active lines.

The achieved agreement between our experimental results [23-28] and the aforementioned theoretical predictions [5-12] is better in comparison to previous characterizations of $\mathrm{C}_{84}$ samples (partially separated isomers), from other separation processes, by other IR techniques $[18,19]$.

Whereas there is a good correlation between our experimental results [23-28] and the theoretical calculations [512], in the previous experimental IR spectrum of the main chromatographically purified fraction of the higher fullerene $\mathrm{C}_{84}$ (partially separated isomers, presented from 400 to $1650 \mathrm{~cm}^{-1}$ ) [18], as well as in the next IR spectrum of the obtained $\mathrm{C}_{84}-\mathrm{D}_{2}$ fraction from another separation process (presented from 484 to $1631 \mathrm{~cm}^{-1}$ ) [19], some discrepancies of the general pattern and vibrational frequencies with the theoretical predictions for the most abundant, stable $\mathrm{C}_{84}$ isomer of $\mathrm{D}_{2}$ symmetry (the $\mathrm{C}_{84}-\mathrm{D}_{2}: 22$ isomer) [5-12] appeared in the significant spectral regions from ca. 450 to $850 \mathrm{~cm}^{-1}$, as well as from ca. $1050 \mathrm{~cm}^{-1}$ to $1650 \mathrm{~cm}^{-1}$. The main disagreement [5-12] is the appearance of the three 
strong, dominant absorption bands in the first relevant part of the spectrum at 792 and 794 and the most intense $648 \mathrm{~cm}^{-1}$ $[18,19]$, unlike our results.

There is a general agreement between most of the vibration modes reported in the previous spectrum of the $\mathrm{C}_{84^{-}}$ $\mathrm{D}_{2}$ fraction [19], as well as in another study [18] and those observed in this work. However, significant changes of relative intensities of certain absorption bands were observed. Characteristic and the main, dominant absorption bands were registered in the second relevant part of the spectrum.

In Table 2, the IR absorption bands of the chromatographically purified $\mathrm{C}_{84}-\mathrm{D}_{2}: 22$ samples are reported as measured in this work at $23^{\circ} \mathrm{C}$ in comparison with the recent data for the $\mathrm{C}_{84}$ sample (mixture of isomers) at different temperatures [52], as well as with the theoretical calculations by the QCFF/PI method [9].

The original experimentally obtained IR spectrum of the chromatographically isolated $\mathrm{C}_{84}-\mathrm{D}_{2}: 22$ sample in this research is presented in Figure 2 (Table 2, first IR).

There is a considerable change of intensity of IR bands in our spectrum of $\mathrm{C}_{84}-\mathrm{D}_{2}: 22$, in comparison to IR spectra of the $\mathrm{C}_{84}$ sample (mixture of isomers) at different temperatures. The main characteristics of the reported spectra [52] are similar. However, the intensity of certain infrared bands of $\mathrm{C}_{84}$ is changing significantly with temperature.

The most intense, dominant absorption bands in our spectrum appear in the second relevant part. The first group is present between absorption band at $1122 \mathrm{~cm}^{-1}$, with the neighboring features at 1107 and $1095 \mathrm{~cm}^{-1}$, and the most intense maximum in the spectrum at $1385 \mathrm{~cm}^{-1}$, with a neighboring absorption at $1398 \mathrm{~cm}^{-1}$. Pronounced bands also appear around $1600 \mathrm{~cm}^{-1}$, between the next intense maxima at $1456 \mathrm{~cm}^{-1}$, with a neighbor very weak absorption at $1433 \mathrm{~cm}^{-1}$, and at $1731 \mathrm{~cm}^{-1}$. A cluster of minor bands appears from 1494 to $1558 \mathrm{~cm}^{-1}$ at the wave numbers higher than the main band.

The group of bands with the main maximum at $1433 \mathrm{~cm}^{-1}$ in the second relevant part of the recent spectra of $\mathrm{C}_{84}$ is more intense than the following band at $1384 \mathrm{~cm}^{-1}$ at $-170^{\circ} \mathrm{C}$. However, at $+50^{\circ} \mathrm{C}$ and $+250^{\circ} \mathrm{C}$, the two groups of bands, although less defined, have approximately the same intensity. Similarly, in the mentioned previous spectrum of $\mathrm{C}_{84}$ (partially separated isomers) [18], as well as in the IR spectrum of the obtained $\mathrm{C}_{84}-\mathrm{D}_{2}$ fraction at room temperature [19], the two main, most intense bands in the second part of approximately the same intensity appear at 1432 and $1383 \mathrm{~cm}^{-1}$. Relatively broad feature at $1730 \mathrm{~cm}^{-1}$ was recorded in the IR spectrum of $\mathrm{C}_{84}$ at $-170^{\circ} \mathrm{C}$ and $+250^{\circ} \mathrm{C}$, but not so evident at $50^{\circ} \mathrm{C}$ [52].

In the first relevant part of our spectrum, a series of characteristic sharp absorption maxima are observed around $780 \mathrm{~cm}^{-1}$, at $699,711,746,779,826$, and $843 \mathrm{~cm}^{-1}$, with the neighbor very weak absorption at $884 \mathrm{~cm}^{-1}$. The absorption bands around $635 \mathrm{~cm}^{-1}$ (from 574 to $657 \mathrm{~cm}^{-1}$ ) and $473 \mathrm{~cm}^{-1}$ (from 402 to $540 \mathrm{~cm}^{-1}$ ) follow them. Weak feature at $647 \mathrm{~cm}^{-1}$ is hardly observable. A group of minor bands is registered from 516 to $574 \mathrm{~cm}^{-1}$.

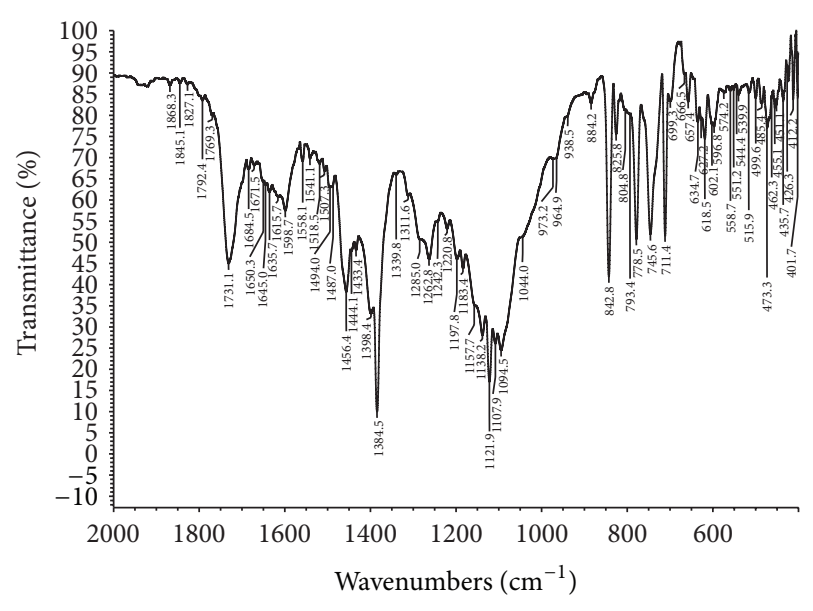

FIGURE 2: The IR spectrum of the chromatographically purified $\mathrm{C}_{84}-\mathrm{D}_{2}: 22$ sample.

The main bands in the first part of the recent spectra of $\mathrm{C}_{84}$ at different temperatures [52] appear at 470 and 647 and the most intense at $797 \mathrm{~cm}^{-1}$. The two distinct bands at 670 and $648 \mathrm{~cm}^{-1}$ observed at $-170^{\circ} \mathrm{C}$ appear much less intense at $+50^{\circ} \mathrm{C}$ and $+250^{\circ} \mathrm{C}$ with the band at $670 \mathrm{~cm}^{-1}$ reduced to a weak feature. The most intense bands in the previous spectrum of $\mathrm{C}_{84}$ (partially separated isomers [18]), as well as in the IR spectrum of the obtained $\mathrm{C}_{84}-\mathrm{D}_{2}$ fraction, appear at 648,792 , and $797 \mathrm{~cm}^{-1}[19]$.

There are no pronounced absorption bands in our spectrum of $\mathrm{C}_{84}-\mathrm{D}_{2}: 22$ between ca. 850 and $1050 \mathrm{~cm}^{-1}$. Several weak features were observed. In the case of $\mathrm{C}_{84}$ sample, the FT-IR spectra [52] show a dominant, broad band centered at $1077 \mathrm{~cm}^{-1}$ and $1031 \mathrm{~cm}^{-1}$, which were already reported in the literature $[5-12,18,19]$, but not as intense as detected recently [52].

The general pattern of our spectrum, its fine structure with more splitter lines, and all of the experimentally observed IR absorption bands, in the entire spectral region relevant for the identification of fullerenes, are in excellent agreement with the aforementioned semiempirical [5-10], as well as with the ab initio HF [11], and DFT theoretical calculations [12] for the most abundant, stable $\mathrm{C}_{84}$ isomer of $\mathrm{D}_{2}$ symmetry.

The presented results in this study indicate that the aforementioned semiempirical [5-10], ab initio, and DFT calculations [11, 12] provide an overall excellent prediction of the IR spectrum and vibrational frequencies of the most abundant stable isomer of the higher fullerenes $\mathrm{C}_{84}$ with $\mathrm{D}_{2}$ symmetry. A one to one assignment is achieved over the entire relevant spectral region for fullerenes. Only in a few cases is the accuracy not enough to permit a one to one assignment, as when two IR bands are separated by a small frequency interval. Their assignment can be supported by considering the frequencies obtained by the ab initio and DFT calculations $[11,12]$ in addition to the frequencies obtained by the semiempirical PM3, AM1, MNDO, and QCFF/PI, as well as by the TB potential calculations [5-10], and conversely. 
TABLE 2: Experimental and theoretically calculated absorption bands of $\mathrm{C}_{84}$ fullerene between 400 and $1770 \mathrm{~cm}^{-1}$.

\begin{tabular}{|c|c|c|c|c|c|c|}
\hline \multirow{4}{*}{$\begin{array}{l}\text { Calculated } \\
\text { Negri et al. } \\
\text { Absorption bands } \\
\left(\mathrm{cm}^{-1}\right)\end{array}$} & \multicolumn{6}{|c|}{ Experimental } \\
\hline & \multicolumn{3}{|c|}{ This work } & \multicolumn{3}{|c|}{ Cataldo et al. ${ }^{\mathrm{b}}$} \\
\hline & s IR1 & $\operatorname{IR} 2^{\mathrm{c}}$ & IR3 & $-170^{\circ} \mathrm{C}$ & $+50^{\circ} \mathrm{C}$ & $+250^{\circ} \mathrm{C}$ \\
\hline & $\left(\mathrm{cm}^{-1}\right)$ & $\left(\mathrm{cm}^{-1}\right)$ & $\left(\mathrm{cm}^{-1}\right)$ & $\left(\mathrm{cm}^{-1}\right)$ & $\left(\mathrm{cm}^{-1}\right)$ & $\left(\mathrm{cm}^{-1}\right)$ \\
\hline & 402 & & 402 & & & \\
\hline & 412 & & 409 & & & \\
\hline & 427 & 419 & & 423 & 427 & 428 \\
\hline 437 & 436 & 434 & 434 & & & \\
\hline 440 & & 440 & & 446 & 444 & 442 \\
\hline 449 & & & 447 & & & \\
\hline 451 & 451 & 451 & & & & \\
\hline 452 & 455 & 456 & & & & \\
\hline 461 & 462 & 464 & 464 & & & \\
\hline 472 & 473 & & & 473 & 470 & 470 \\
\hline 479 & & 476 & 479 & & & \\
\hline 483 & 485 & & & & & \\
\hline 499 & 497 & & 494 & 493 & 493 & 491 \\
\hline 513 & 516 & 515 & 517 & & & \\
\hline 533 & & 532 & 533 & & & \\
\hline 539 & 540 & & & & & \\
\hline 552 & 551 & 548 & 546 & & & \\
\hline 558 & 559 & & 560 & 560 & 559 & \\
\hline 572 & & 570 & & & & \\
\hline 575 & 573 & & 575 & & & \\
\hline 578 & & 582 & & 582 & 582 & 579 \\
\hline 589 & & & 588 & & & \\
\hline 593 & 597 & 593 & & & & \\
\hline 610 & 602 & 605 & & & & \\
\hline 618 & 618 & 616 & 616 & & & \\
\hline 633 & 635 & 632 & 631 & & & \\
\hline 652 & & 647 & 647 & 648 & 647 & 648 \\
\hline 659 & 657 & & 656 & & & \\
\hline 669 & & 669 & & 670 & 669 & 670 \\
\hline 699 & 699 & 700 & & & & \\
\hline 703 & & & 703 & & 703 & 703 \\
\hline 713 & 711 & 711 & & & & \\
\hline 720 & & & 722 & & & \\
\hline 740 & 746 & 743 & 741 & 763 & 763 & 737 \\
\hline 753 & & & 752 & & & \\
\hline 777 & 778 & 777 & 777 & & & \\
\hline 791 & 793 & & & 794 & 797 & 795 \\
\hline 806 & 805 & 801 & & & & \\
\hline 822 & & & 820 & & & \\
\hline 827 & 826 & & & & & \\
\hline 843 & 843 & 842 & 844 & & 845 & 845 \\
\hline 856 & & & 857 & & & \\
\hline 883 & 885 & & & & & \\
\hline 909 & & & 908 & & & \\
\hline \multirow[t]{2}{*}{941} & 939 & & & & & \\
\hline & 965 & 967 & & & & \\
\hline
\end{tabular}

TABLE 2: Continued.

\begin{tabular}{|c|c|c|c|c|c|c|}
\hline \multirow{3}{*}{$\begin{array}{l}\text { Calculated } \\
\text { Negri et al. }^{\text {a }} \\
\text { Absorption bands } \\
\left(\mathrm{cm}^{-1}\right)\end{array}$} & \multicolumn{6}{|c|}{ Experimental } \\
\hline & \multicolumn{3}{|c|}{ This work } & \multicolumn{3}{|c|}{ Cataldo et al. ${ }^{\mathrm{b}}$} \\
\hline & $\begin{array}{c}\text { IR1 } \\
\left(\mathrm{cm}^{-1}\right)\end{array}$ & $\begin{array}{c}\mathrm{IR} 2^{\mathrm{c}} \\
\left(\mathrm{cm}^{-1}\right)\end{array}$ & $\begin{array}{c}\text { IR3 } \\
\left(\mathrm{cm}^{-1}\right)\end{array}$ & $\begin{array}{l}-170^{\circ} \mathrm{C} \\
\left(\mathrm{cm}^{-1}\right)\end{array}$ & $\begin{array}{l}+50^{\circ} \mathrm{C} \\
\left(\mathrm{cm}^{-1}\right)\end{array}$ & $\begin{array}{l}+250^{\circ} \mathrm{C} \\
\left(\mathrm{cm}^{-1}\right)\end{array}$ \\
\hline 973 & 973 & & 974 & & & \\
\hline 1029 & & 1030 & 1028 & 1031 & 1031 & 1029 \\
\hline 1041 & 1044 & & & & & \\
\hline 1077 & & 1080 & 1078 & 1077 & & 1078 \\
\hline 1093 & 1094 & & & 1092 & & \\
\hline 1113 & 1107 & & & & & \\
\hline 1129 & 1122 & 1122 & 1123 & & & \\
\hline 1132 & 1138 & & & 1142 & & \\
\hline 1164 & & & 1169 & & & \\
\hline 1187 & 1183 & 1187 & & & & \\
\hline 1190 & 1198 & & & & & \\
\hline 1208 & & & 1208 & & & \\
\hline 1211 & & & 1211 & & & \\
\hline 1219 & 1219 & & & & & \\
\hline 1241 & 1242 & & & & & \\
\hline 1247 & & & 1247 & & & \\
\hline 1266 & 1263 & 1264 & 1263 & 1258 & 1257 & 1261 \\
\hline 1290 & 1285 & & & & & \\
\hline 1299 & & 1304 & 1304 & & & \\
\hline 1317 & 1312 & & & & & 1319 \\
\hline 1327 & & & & 1324 & & \\
\hline 1340 & 1340 & & & 1339 & & \\
\hline 1358 & & & & & & 1360 \\
\hline 1383 & 1384 & 1385 & 1377 & 1384 & 1378 & 1377 \\
\hline 1398 & 1398 & 1400 & & & & \\
\hline 1416 & & & & 1418 & & \\
\hline 1433 & 1433 & & & 1433 & 1432 & 1428 \\
\hline 1452 & 1456 & & & 1456 & 1454 & 1455 \\
\hline 1466 & & 1465 & 1463 & & & \\
\hline 1494 & 1494 & & & & & \\
\hline 1501 & 1507 & & 1509 & 1505 & 1504 & 1504 \\
\hline 1522 & 1518 & & & 1520 & & \\
\hline 1545 & 1540 & 1541 & 1542 & 1540 & 1535 & \\
\hline 1564 & 1558 & 1558 & 1558 & 1558 & 1557 & 1556 \\
\hline 1596 & 1599 & & 1602 & & & \\
\hline 1612 & 1616 & 1616 & & 1616 & 1610 & 1622 \\
\hline 1646 & 1635 & & & 1633 & 1631 & \\
\hline 1647 & 1645 & 1650 & 1656 & 1654 & & 1647 \\
\hline 1672 & 1671 & & & & & \\
\hline \multirow[t]{2}{*}{1683} & 1684 & 1686 & & 1683 & & \\
\hline & & & & 1697 & & \\
\hline \multirow[t]{3}{*}{1711} & & & & 1715 & 1708 & 1714 \\
\hline & 1731 & 1732 & 1735 & 1733 & 1729 & 1729 \\
\hline & 1769 & & & 1772 & 1788 & 1766 \\
\hline
\end{tabular}

${ }^{a}$ Reference [9].

${ }^{\mathrm{b}}$ Reference [52].

${ }^{\mathrm{c}}$ Reference [28]. 
These results remove the need for the assumptions of possible errors of the theoretical calculations for the $\mathrm{C}_{76}$ and $\mathrm{C}_{84}$ isomers with $\mathrm{D}_{2}$ symmetry $[5-12,29,30]$ in the significant spectral regions, based on the previous comparisons with partial experimental results [16-19]. They provide the evidence of their validity over the entire relevant region.

In this study also, the unique UV/VIS absorption maxima of the chromatographically purified $\mathrm{C}_{76}$ and $\mathrm{C}_{84}$ isomers of $\mathrm{D}_{2}$ symmetry are registered over the entire region from 200 to $900 \mathrm{~nm}$, including the most significant region from 200 to $400 \mathrm{~nm}$ where fullerenes have allowed transitions and intensively absorb.

The experimentally obtained UV/VIS spectrum of the chromatographically isolated $\mathrm{C}_{76}-\mathrm{D}_{2}$ sample is presented in Figure 3. Dominant UV absorption maxima are present at 256 and $329 \mathrm{~nm}$. Their relative intensities are decreased in comparison to the spectra of the previous chromatographically purified $\mathrm{C}_{60}$ and $\mathrm{C}_{70}$ fractions $[23,24,36-38]$. The third dominant, most intense band appears as a shoulder at ca. $210 \mathrm{~nm}$. The absorption is prolonged to the region below $200 \mathrm{~nm}$, which is characteristic for $\mathrm{C}_{76}$. Pronounced $\mathrm{C}_{76}$ shoulder is registered at $275 \mathrm{~nm}$, as well as its shoulders at ca. $230,285,350$, and $378 \mathrm{~nm}$. In the visible part, a weaker $\mathrm{C}_{76}$ band appears at $405 \mathrm{~nm}$. Absorption is prolonged to $900 \mathrm{~nm}$.

In the UV/VIS spectrum of the purified $\mathrm{C}_{76}$ sample from much diluted hexane solution to complete discoloring, we also recorded for comparison a series of more splitter absorption maxima which are registered at 229 and $285 \mathrm{~nm}$, with the neighbors at ca. 256 and $275 \mathrm{~nm}$, as well as at $328,350,378$, and $405 \mathrm{~nm}$. This spectrum has shown some differences and some similarities compared to the mentioned spectrum of $\mathrm{C}_{76}$ measured from more concentrated solution in hexane. With the change of solution concentration, such as significant dilution, the appearance of several new close absorption maxima or the fine structure may occur.

The experimentally obtained UV/VIS absorption spectrum of the chromatographically isolated sample of the most abundant, stable isomer of the higher fullerene $\mathrm{C}_{84}$ is presented in Figure 4. The most intense maximum is present at $239 \mathrm{~nm}$, with a shoulder at $230 \mathrm{~nm}$. The next intense absorption maximum appears at 272 , with the neighboring bands at 251,261, and $287 \mathrm{~nm}$. They are followed by the bands at $333,305,318,357$, and $381 \mathrm{~nm}$.

Complete configuration of absorption and all the observed absorption bands in the spectra of the purified $\mathrm{C}_{76}-\mathrm{D}_{2}$ and $\mathrm{C}_{84}-\mathrm{D}_{2}: 22$ samples is in good correlation with the semiempirical QCFF/PI, TB, and DFT theoretical predictions for these molecules [48-51], which behave as electrondeficient arenes. It also correlates well with the previously obtained PES of $\mathrm{C}_{76}$ and $\mathrm{C}_{84}$ [49-51].

In the previous work of Jinno et al. [39, 40], the UV/VIS spectra of the chromatographically purified $\mathrm{C}_{76}$ and $\mathrm{C}_{84}$ fractions were recorded from the mixture of acetonitrile and toluene $(55: 45$ or $50: 50, \mathrm{v} / \mathrm{v})$ in the region from 300 to $600 \mathrm{~nm}$. Kikuchi et al. [41, 42] presented the optical absorption of the purified higher fullerenes $\mathrm{C}_{76}$ and $\mathrm{C}_{84}$ dissolved in benzene, in the range of 500 to $1100 \mathrm{~nm}$. Ettl et al. [16] and Diederich and Whetten [43] reported the UV/VIS spectra of the molecule $C_{76}$, as well as that of

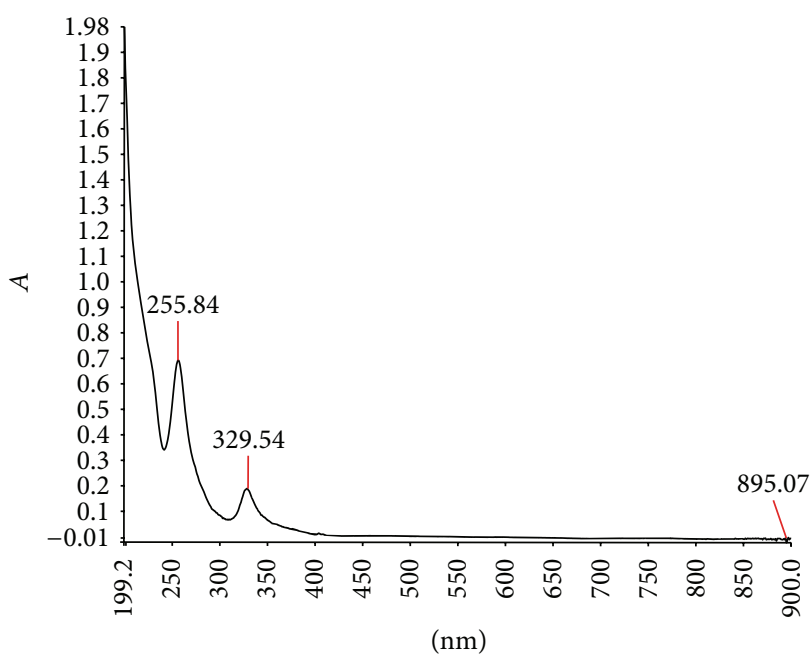

FIGURE 3: The UV/VIS spectrum of the chromatographically purified $\mathrm{C}_{76}-\mathrm{D}_{2}$ sample.

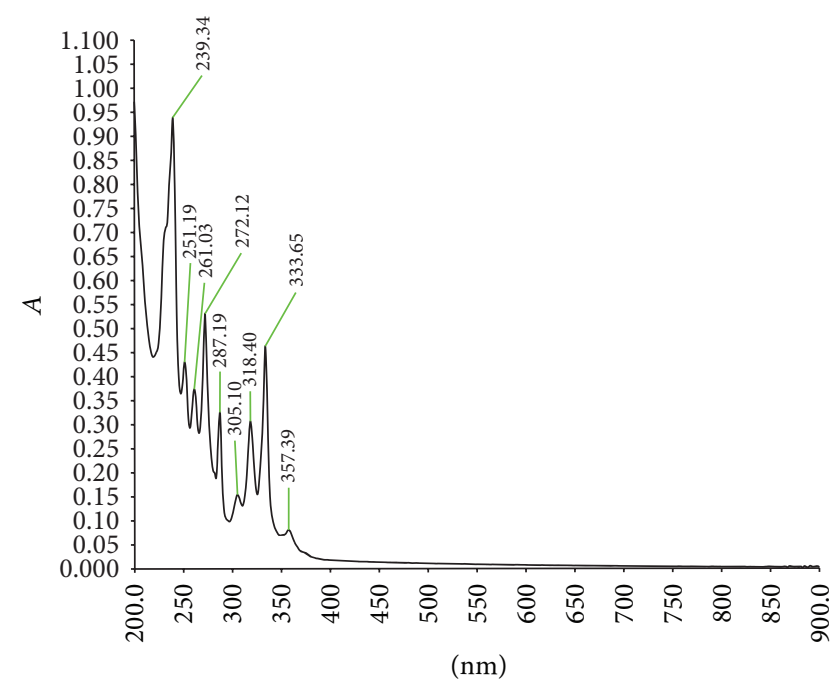

FIGURE 4: The UV/VIS spectrum of the chromatographically purified $\mathrm{C}_{84}-\mathrm{D}_{2}: 22$ sample.

other higher fullerenes from dichloromethane solutions, in different regions. In the previous paper by Diederich et al. [14], the UV/VIS spectrum of $\mathrm{C}_{76}$ recorded from very diluted solution in hexane was presented in the region from 200 to $800 \mathrm{~nm}$. Locations of $\mathrm{C}_{84}$ absorption bands, measured from 280 to $912 \mathrm{~nm}$, from dichloromethane solution were only mentioned in this paper. Dennis et al. reported the UV/VIS/NIR absorption spectra of the isolated fractions of the $\mathrm{D}_{2}(\mathrm{IV})$ and $\mathrm{D}_{2 \mathrm{~d}}$ (II) isomers, as well as of other six minor isomers of the higher fullerene $\mathrm{C}_{84}$, from 400 to $2000 \mathrm{~nm}$ $[44,45]$. Xenogiannopoulou et al. presented the absorption spectra of $\mathrm{C}_{84}$ and its $\mathrm{D}_{2}(\mathrm{IV})$ and $\mathrm{D}_{2 \mathrm{~d}}(\mathrm{II})$ isomers dissolved in toluene in the range of ca. $300-350 \mathrm{~nm}$ to $1100 \mathrm{~nm}[46,47]$.

All the presented results indicate the achieved progress in the spectroscopic characterization and chromatographic separation of the $\mathrm{C}_{76}$ and $\mathrm{C}_{84}$ isomers of $\mathrm{D}_{2}$ symmetry, as well 
as of the basic fullerenes, due to the application of the new and advanced experimental methods and processes.

Identification of fullerenes in the chromatographically purified fractions, as well as in the obtained extracts, was performed using determined IR and UV/VIS techniques that have not been presented for the higher fullerenes before.

The results of UV/VIS analysis are in agreement with the results of IR analysis. Characteristic properties, the unique and new absorption bands, and changes of relative intensities and locations of absorption maxima are observed, showing isolation and separation of the basic and the higher fullerenes in the similar, regular way within the several different original, advanced separation processes [22-28].

The obtained original IR and electronic absorption spectra of the isolated $\mathrm{C}_{76}-\mathrm{D}_{2}$ and $\mathrm{C}_{84}-\mathrm{D}_{2}: 22$ isomers, in the spectral regions relevant for the identification of fullerenes, where they intensively absorb, are in excellent agreement with the several theoretical predictions for these molecules, which has not been previously presented.

For the first time, the validity of semiempirical, ab initio, and DFT calculations in predicting the general pattern of IR absorption and the vibrational frequencies, as well as the molecular electronic structure of the stable $\mathrm{C}_{76}$ and $\mathrm{C}_{84}$ isomers of $\mathrm{D}_{2}$ symmetry, is confirmed over the entire relevant spectral range, based on comparison with our recent experimental results.

\section{Conclusion}

The obtained excellent correlation between the experimentally observed general pattern of IR absorption and vibrational frequencies of the isolated stable isomers of the higher fullerenes $\mathrm{C}_{76}$ and $\mathrm{C}_{84}$ isomers with $\mathrm{D}_{2}$ symmetry [22$28]$ and the theoretical predictions $[5-12,29,30]$ for these molecules is presented in this paper. These results provide the first significant experimental evidence of validity of the aforementioned semiempirical, ab initio, and DFT calculations for the $\mathrm{C}_{76}-\mathrm{D}_{2}[29,30]$ and the $\mathrm{C}_{84}-\mathrm{D}_{2}: 22$ [5-12] isomers over the entire relevant spectral region, from ca. 450 to $1650 \mathrm{~cm}^{-1}$.

The experimentally obtained electronic absorption of the isolated $\mathrm{C}_{76}$ and $\mathrm{C}_{84}$ isomers of $\mathrm{D}_{2}$ symmetry over the relevant region from 200 to $900 \mathrm{~nm}$, including the most significant region from 200 to $400 \mathrm{~nm}$ [22-28], is also in very good correlation with the previous semiempirical QCFF/PI, TB, and DFT theoretical predictions for these molecules [48-51].

It is important to mention also that the obtained generally good correlation between the overall configuration of absorption in our recent experimental IR spectra of the neutral solid $\mathrm{C}_{76}$ [22-28] and the next obtained, most recent IRMPED spectrum of the unsolvated gas phase $\mathrm{C}_{76}{ }^{2-}[30]$, as well as with the adequate most recent B3LYP/TZVP DFT calculations [30], provides the significant experimental evidence that the dianionic molecule retains its symmetry (i.e., $D_{2}$ point group) with ${ }^{1} \mathrm{~A}_{1}$ ground state with respect to the neutral cage.

These results are of great importance for further possible and even more sophisticated calculations of vibrational properties and molecular electronic structure of fullerenes and other molecules.
The presented original spectra in this study, as well as their comparison with the recent spectra of $\mathrm{C}_{76}$ and $\mathrm{C}_{84}$ (mixture of isomers) at different temperatures [52], will significantly contribute to better understanding of the IR and UV/VIS optical absorption properties of the higher fullerenes $\mathrm{C}_{76}$ and $\mathrm{C}_{84}$, and their stable isomers with $\mathrm{D}_{2}$ symmetry, as well as of fullerenes generally. They will enable easier identification of $\mathrm{C}_{76}, \mathrm{C}_{84}$, and its most abundant isomer, as well as of $\mathrm{C}_{60}$ and $\mathrm{C}_{70}$, either in artificially synthesized carbon soot or in natural resources in space and on Earth.

Isolated fullerenes and their derivatives are important for the applications in electronic and optical devices, superconductors, semiconductors, solar cells, optical limiting, sensors, polymers, nanophotonic materials, lenses with optical absorption properties closer to human eye light sensitivity, diagnostic and therapeutic agents, encapsulation of metal atoms and radio isotopes, targeted drug and gene delivery, free radicals scavengers, health and environment protection, DNA cleavage, antibacterial and antiviral agents, water purification, storage of hydrogen, high energetic batteries, lubricants, synthesis of diamond, catalysts, and so forth.

\section{Conflict of Interests}

The authors declare that there is no conflict of interests regarding the publication of this paper.

\section{Acknowledgments}

The authors are grateful to the Ministry of Education, Science, and Technological Development of the Republic of Serbia and to the University of Belgrade for financial support of this research (Project III 45009).

\section{References}

[1] D. E. Manolopoulos, "Faraday communications. Proposal of a chiral structure for the fullerene $\mathrm{C}_{76}$ ", Journal of the Chemical Society, Faraday Transactions, vol. 87, no. 17, pp. 2861-2862, 1991.

[2] D. E. Manolopoulos and P. W. Fowler, "Molecular graphs, point groups, and fullerenes," The Journal of Chemical Physics, vol. 96, no. 10, pp. 7603-7614, 1992.

[3] D. E. Manolopoulos, P. W. Fowler, R. Taylor, H. W. Kroto, and D. R. M. Walton, "Faraday communications. an end to the search for the ground state of $\mathrm{C}_{84}$ ?" Journal of the Chemical Society, Faraday Transactions, vol. 88, no. 20, pp. 3117-3118, 1992.

[4] B. L. Zhang, C. Z. Wang, and K. M. Ho, "Search for the groundstate structure of $\mathrm{C}_{84}$," The Journal of Chemical Physics, vol. 96, no. 9, pp. 7183-7185, 1992.

[5] M. Hulman, T. Pichler, H. Kuzmany, F. Zerbetto, E. Yamamoto, and H. N. Shinohara, "Vibrational structure of $\mathrm{C}_{84}$ and $\mathrm{Sc}_{2} @ \mathrm{C}_{84}$ analyzed by IR spectroscopy," Journal of Molecular Structure, vol. 408-409, pp. 359-362, 1997.

[6] G. Von Helden, I. Holleman, M. Putter, A. J. A. van Roij, and G. Meijer, "Infrared resonance enhanced multi-photon ionization spectroscopy of $\mathrm{C}_{84}$," Chemical Physics Letters, vol. 299, no. 2, pp. 171-176, 1999.

[7] J. J. P. Stewart, "Optimization of parameters for semiempirical methods I. Method," Journal of Computational Chemistry, vol. 10, pp. 209-220, 1989. 
[8] D. Bakowies, M. Kolb, W. Thiel, S. Richard, R. Alhrichs, and M. M. Kappes, "Quantum-chemical study of $\mathrm{C}_{84}$ fulleren isomers," Chemical Physics Letters, vol. 200, no. 4, pp. 411-417, 1992.

[9] F. Negri, G. Orlandi, and F. Zerbetto, "Prediction of the structure and the vibrational frequencies of a $\mathrm{C}_{84}$ isomer of $\mathrm{D}_{2}$ symmetry," Chemical Physics Letters, vol. 189, no. 6, pp. 495-498, 1992.

[10] B. L. Zhang, C. Z. Wang, and K. M. Ho, "Vibrational spectra of $\mathrm{C}_{84}$ isomers," Physical Review B, vol. 47, no. 3, pp. 1643-1646, 1993.

[11] T. Nishikawa, T. Kinoshita, S. Nanbu, and M. Aoyagi, "A theoretical study on vibrational spectra of $\mathrm{C}_{84}$ fullerenes: results for $\mathrm{C}_{2}, \mathrm{D}_{2}$, and $\mathrm{D}_{2 d}$ isomers," Journal of Molecular Structure, vol. 461-462, pp. 453-461, 1999.

[12] H. F. Bettinger and G. E. Scuseria, "The infrared vibrational spectra of the two major $\mathrm{C}_{84}$ isomers," Chemical Physics Letters, vol. 332, no. 1-2, pp. 35-42, 2000.

[13] K. Kikuchi, N. Nakahara, T. Wakabayashi et al., "NMR characterization of isomers of $\mathrm{C}_{78}, \mathrm{C}_{82}$ and $\mathrm{C}_{84}$ fullerenes," Nature, vol. 357, no. 6374, pp. 142-145, 1992.

[14] F. Diederich, R. Ettl, Y. Rubin et al., "The higher fullerenes: isolation and characterization of $\mathrm{C}_{76}, \mathrm{C}_{84}, \mathrm{C}_{90}, \mathrm{C}_{94}$, and $\mathrm{C}_{70} \mathrm{O}$, an oxide of $\mathrm{D}_{5 h}-\mathrm{C}_{70}$," Science, vol. 252, no. 5005, pp. 548-551, 1991.

[15] R. Taylor, G. J. Langley, A. G. Avent, T. J. S. Dennis, H. W. Kroto, and D. R. M. Walton, " ${ }^{13} \mathrm{C}$ NMR spectroscopy of $\mathrm{C}_{76}$, $\mathrm{C}_{78}, \mathrm{C}_{84}$ and mixtures of $\mathrm{C}_{86}-\mathrm{C}_{102}$ : anomalous chromatographic behavior of $\mathrm{C}_{82}$, an evidence of $\mathrm{C}_{70} \mathrm{H}_{12}$," Journal of the Chemical Society, Perkin Transactions, vol. 2, pp. 1029-1036, 1993.

[16] R. Ettl, I. Chao, F. Diederich, and R. L. Whetten, "Isolation of $\mathrm{C}_{76}$, a chiral $\mathrm{D}_{2}$ allotrope of carbon," Nature, vol. 353 , no. 6340 , pp. 149-153, 1991.

[17] R. H. Michel, H. Schreiber, R. Gierden et al., "Vibrational spectroscopy of purified $\mathrm{C}_{76}$," Berichte der Bunsengesellschaft für physikalische Chemie, vol. 98, no. 7, pp. 975-978, 1994.

[18] A. G. Avent, D. Dubois, A. Pénicaud, and R. Taylor, "The minor isomers and IR spectrum of [84]fullerene," Journal of the Chemical Society. Perkin Transactions 2, no. 10, pp. 1907-1910, 1997.

[19] T. J. S. Dennis, M. Hulman, H. Kuzmany, and H. Shinohara, "Vibrational infrared spectra of the two major isomers of [84]fullerene: $\mathrm{C}_{84} D_{2}$ (IV) and $\mathrm{C}_{84} D_{2 d}$ (II)," The Journal of Physical Chemistry B, vol. 104, no. 23, pp. 5411-5413, 2000.

[20] M. Krause, M. Hulman, H. Kuzmany et al., "Low-energy vibrations in $\mathrm{Sc}_{2} @ \mathrm{C}_{84}$ and $\mathrm{Tm} @ \mathrm{C}_{82}$ metallofullerenes with different carbon cages," Journal of Molecular Structure, vol. 521, no. 1-3, pp. 325-340, 2000.

[21] M. Krause, M. Hulman, H. Kuzmany, T. J. S. Dennis, M. Inakuma, and H. Shinohara, "Diatomic metal encapsulates in fullerene cages: a Raman and infrared analysis of $\mathrm{C}_{84}$ and $\mathrm{Sc}_{2} @ \mathrm{C}_{84}$ with $\mathrm{D}_{2 d}$ symmetry," Journal of Chemical Physics, vol. 111, no. 17, pp. 7976-7984, 1999.

[22] T. Jovanovic and D. Koruga, "The electronic structure and vibrational frequencies of the stable $\mathrm{C}_{76}$ isomer of $\mathrm{D}_{2}$ symmetry: theory and experiment," Chemical Physics Letters, vol. 577, pp. 68-70, 2013.

[23] T. Jovanovic, D. Koruga, B. Jovancicevic, and J. Simic-Krstic, "Advancement of the process for extraction, chromatography and characterization of fullerenes, Fuller," Fullerenes Nanotubes and Carbon Nanostructures, vol. 17, no. 2, pp. 135-150, 2009.
[24] T. Jovanovic, D. Koruga, B. Jovancicevic, V. Vajs, and G. Devic, "Comparative spectroscopic characterization of the basic and the higher fullerenes," Fullerenes Nanotubes and Carbon Nanostructures, vol. 21, no. 1, pp. 64-74, 2013.

[25] T. Jovanovic, D. J. Koruga, and B. Jovancicevic, "Isolation and characterization of the higher fullerenes from carbon soot," Fullerenes Nanotubes and Carbon Nanostructures, vol. 19, no. 4, pp. 309-316, 2011.

[26] T. Jovanovic, D. Koruga, and B. Jovancicevic, "Advances in chromatographic separation on $\mathrm{Al}_{2} \mathrm{O}_{3}$ and spectroscopic characterization of the higher fullerenes," Fullerenes Nanotubes and Carbon Nanostructures, vol. 22, no. 4, pp. 384-396, 2014.

[27] T. Jovanovic and D. Koruga, "Recent advances in chromatographic separation and spectroscopic characterization of the higher fullerenes $\mathrm{C}_{76}$ and $\mathrm{C}_{84}$," Recent Patents on Nanotechnology, vol. 8, no. 1, pp. 62-75, 2014.

[28] T. Jovanovic, D. Koruga, and B. Jovancicevic, "The electronic structure and vibrational frequencies of the stable $\mathrm{C}_{84}$ isomer of $\mathrm{D}_{2}$ symmetry: Theory and experiment," Diamond and Related Materials, vol. 44, pp. 44-48, 2014.

[29] G. Orlandi, F. Zerbetto, P. W. Fowler, and D. E. Manolopoulos, "The electronic structure and vibrational frequencies of the stable $\mathrm{C}_{76}$ isomer of $\mathrm{D}_{2}$ symmetry," Chemical Physics Letters, vol. 208, no. 5-6, pp. 441-445, 1993.

[30] O. Hampe, M. Neumaier, A. D. Boese, J. Lemaire, G. NiednerSchatteburg, and M. M. Kappes, "Infrared multiphoton electron detachment spectroscopy of $\mathrm{C}_{76}^{2-}$," The Journal of Chemical Physics, vol. 131, no. 12, Article ID 124306, 2009.

[31] W. Brockner and F. Menzel, "Genetic relationship between intrinsic Raman and infrared fundamental vibrations of the $\mathrm{C}_{60}$ and $\mathrm{C}_{70}$ fullerenes," Journal of Molecular Structure, vol. 378, no. 2, pp. 147-163, 1996.

[32] S.-P. Tseng, M.-Y. Shen, and C.-H. Yu, "A MNDO study of carbon clusters with specifically fitted parameters," Theoretica Chimica Acta, vol. 92, no. 5, pp. 269-280, 1995.

[33] M. Menon, E. Richter, and K. R. Subbaswamy, "Structural and vibrational properties of fullerenes and nanotubes in a nonorthogonal tight-binding scheme," Journal of Chemical Physics, vol. 104, no. 15, pp. 5875-5882, 1996.

[34] F. Negri and G. Orlandi, "The vibrational frequencies of fullerenes from an updated QCFF/PI Hamiltonian," Journal of Physics B: Atomic, Molecular and Optical Physics, vol. 29, no. 21, pp. 5049-5063, 1996.

[35] F. Negri, G. Orlandi, and F. Zerbetto, "QCFF/PI vibrational frequencies of some spherical carbon clusters," Journal of the American Chemical Society, vol. 113, no. 16, pp. 6037-6040, 1991.

[36] T. Jovanovic, D. Koruga, B. Jovancicevic, and J. Simic-Krstic, "Modifications of fullerenes extractions and chromatographies with different solvents," Fullerenes Nanotubes and Carbon Nanostructures, vol. 11, no. 4, pp. 383-394, 2003.

[37] T. Jovanović, D. Koruga, P. Polić, and G. Dević, "Extraction separation and characterization of fullerenes from carbon soot," Materials Science Forum, vol. 413, pp. 59-64, 2003.

[38] T. Jovanovic, D. Koruga, B. Jovancicevic, and J. Simic-Krstic, "Improvement in separation of nanostructured carbon clusters $\mathrm{C}_{60}$ and $\mathrm{C}_{70}$," International Journal of Nanoscience, vol. 2, p. 129, 2003.

[39] K. Jinno, H. Matsui, H. Ohta et al., "Separation and identification of higher fullerenes in soot extract by liquid chromatographymass spectrometry," Chromatographia, vol. 41, no. 5-6, pp. 353-360, 1995. 
[40] K. Jinno, Y. Sato, H. Nagashima, and K. Itoh, "Separtion and identification of higer fullerenes by high-performance liquid chromatography coupled with electrospray ionization mass spectrometry," Journal of Microcolumn Separations, vol. 10, no. 1, pp. 79-88, 1998.

[41] K. Kikuchi, N. Nakahara, T. Wakabayashi et al., "Isolation and identification of fullerene family: $\mathrm{C}_{76}, \mathrm{C}_{78}, \mathrm{C}_{82}, \mathrm{C}_{84}, \mathrm{C}_{90}$ and C $_{96}$," Chemical Physics Letters, vol. 188, no. 3-4, pp. 177-180, 1992.

[42] K. Kikuchi, N. Nakahara, M. Honda et al., "Separation, detection and UV/visible absorption spectra of $\mathrm{C}_{76}, \mathrm{C}_{78}$ and $\mathrm{C}_{84}$ ", Chemistry Letters, vol. 188, pp. 1607-1610, 1991.

[43] F. Diederich and R. L. Whetten, "Beyond $\mathrm{C}_{60}$ : The higher fullerenes," Accounts of Chemical Research, vol. 25, no. 3, pp. 119126, 1992.

[44] T. J. S. Dennis and H. Shinohara, "Isolation and characterization of the two major isomers of [84] fullerene $\left(\mathrm{C}_{84}\right)$," Chemical Communications, no. 5, pp. 619-620, 1998.

[45] T. J. S. Dennis, T. Kai, K. Asato et al., "Isolation and characterization by ${ }^{13} \mathrm{C}$ NMR spectroscopy of [84]fullerene minor isomers," Journal of Physical Chemistry A, vol. 103, no. 44, pp. 8747-8752, 1999.

[46] E. Xenogiannopoulou, E. Koudoumas, N. Tagmatarchis, H. Shinohara, and S. Couris, "Ultrafast third-order nonlinear optical response of $\mathrm{C}_{84}, \mathrm{C}_{84}-\mathrm{D}_{2}$ (IV) and $\mathrm{C}_{84}-\mathrm{D}_{2 d}$ (II)," Chemical Physics Letters, vol. 425, no. 1-3, pp. 110-113, 2006.

[47] E. Xenogiannopoulou, P. Aloukos, and S. Couris, "Optical nonlinearities of $\mathrm{C}_{84}$ fullerenes," Chemical Physics Letters, vol. 432, no. 4-6, pp. 497-501, 2006.

[48] K. Harigaya and S. Abe, "Optical absorption spectra and geometric effects in higher fullerenes," Journal of Physics Condensed Matter, vol. 8, no. 42, pp. 8057-8066, 1996.

[49] S. Saito, S.-I. Sawada, and N. Hamada, "Electronic and geometric structures of $\mathrm{C}_{76}$ and $\mathrm{C}_{84}$," Physical Review $B$, vol. 45 , no. 23, pp. 13845-13848, 1992.

[50] O. T. Ehrler, F. Furche, J. M. Weber, and M. M. Kappes, "Photoelectron spectroscopy of fullerene dianions C76(2-), C78(2-), C84(2-)," The Journal of Chemical Physics, vol. 122, Article ID 094321, 6 pages, 2005.

[51] S. Hino, K. Matsumoto, S. Hasegawa et al., "Ultraviolet photoelectron spectra of $\mathrm{C}_{82}$ and $\mathrm{K}_{x} \mathrm{C}_{82}$," Physical Review $B$, vol. 48, no. 11, pp. 8418-8423, 1993.

[52] F. Cataldo, Y. Hafez, and S. Iglesias-Groth, "FT-IR spectra of fullerenes $\mathrm{C}_{76}, \mathrm{C}_{78}$ and $\mathrm{C}_{84}$ at temperatures between $-180^{\circ} \mathrm{C}$ and $+250^{\circ}$ C, Fullerenes Nanotubes and Carbon Nanostructures, vol. 22, no. 10, pp. 901-913, 2014.

[53] J. Cami, J. Bernard-Salas, E. Peeters, and S. E. Malek, "Detection of $\mathrm{C}_{60}$ and $\mathrm{C}_{70}$ in a young planetary nebula," Science, vol. 329, no. 5996, pp. 1180-1182, 2010.

[54] Y. Zhang and S. Kwok, "Detection of $\mathrm{C}_{60}$ in the protoplanetary nebula IRAS 01005+7910," The Astrophysical Journal, vol. 730, no. 2, article 126, 2011.

[55] C. Gielen, J. Cami, J. Bouwman, E. Peeters, and M. Min, "Carbonaceous molecules in the oxygen-rich circumstellar environment of binary post-AGB stars : $\mathrm{C}_{60}$ fullerenes and polycyclic aromatic hydrocarbons," Astronomy and Astrophysics, vol. 536, article A54, 2011.

[56] K. R. G. Roberts, K. T. Smith, and P. J. Sarre, "Detection of $\mathrm{C}_{60}$ in embedded young stellar objects, a Herbig Ae/Be star and an unusual post-asymptotic giant branch star," Monthly Notices of the Royal Astronomical Society, vol. 421, no. 4, pp. 3277-3285, 2012.
[57] K. Sellgren, M. W. Werner, J. G. Ingalls, J. D. T. Smith, T. M. Carleton, and C. Joblin, "Confirmation of $\mathrm{C}_{60}$ in the reflection nebula NGC 7023," EAS Publications Series, vol. 46, pp. 209-214, 2011.

[58] D. A. García-Hernndez, N. K. Rao, and D. L. Lambert, "Are $\mathrm{C}_{60}$ molecules detectable in circumstellar shells of R Coronae Borealis stars?" Astrophysical Journal, vol. 729, no. 2, article no. 126, 2011 

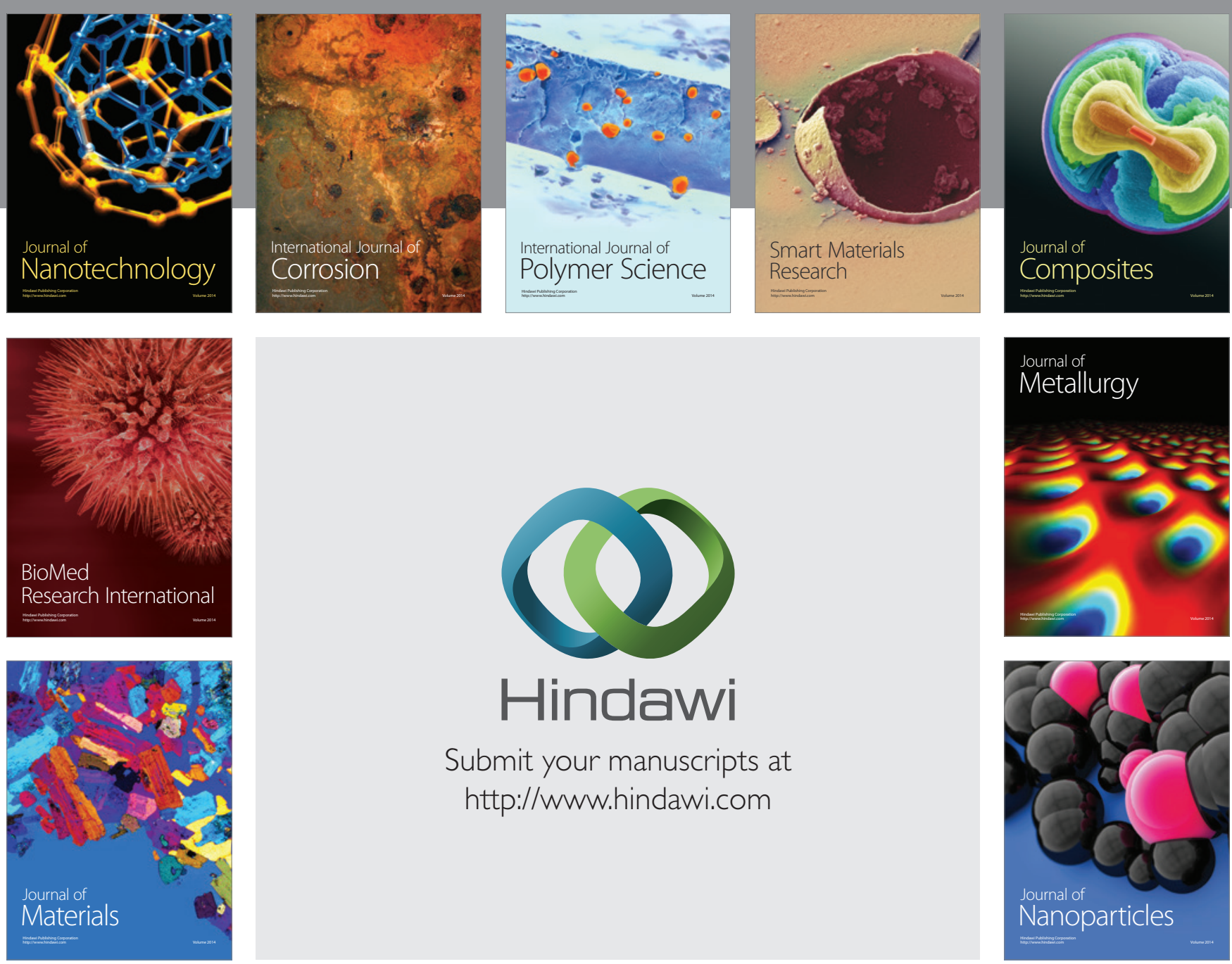

Submit your manuscripts at http://www.hindawi.com
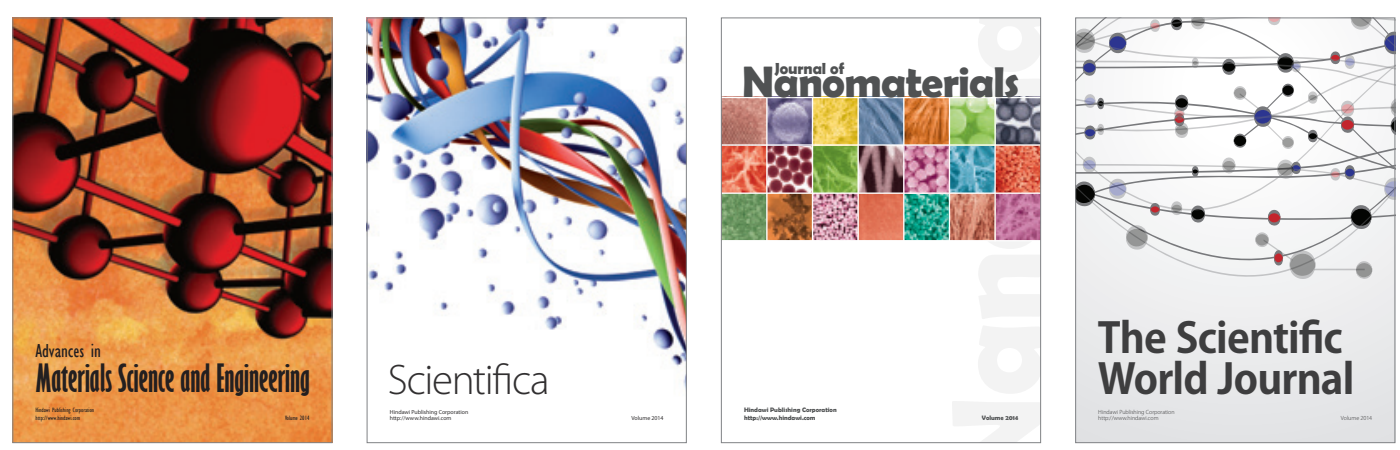

\section{The Scientific World Journal}
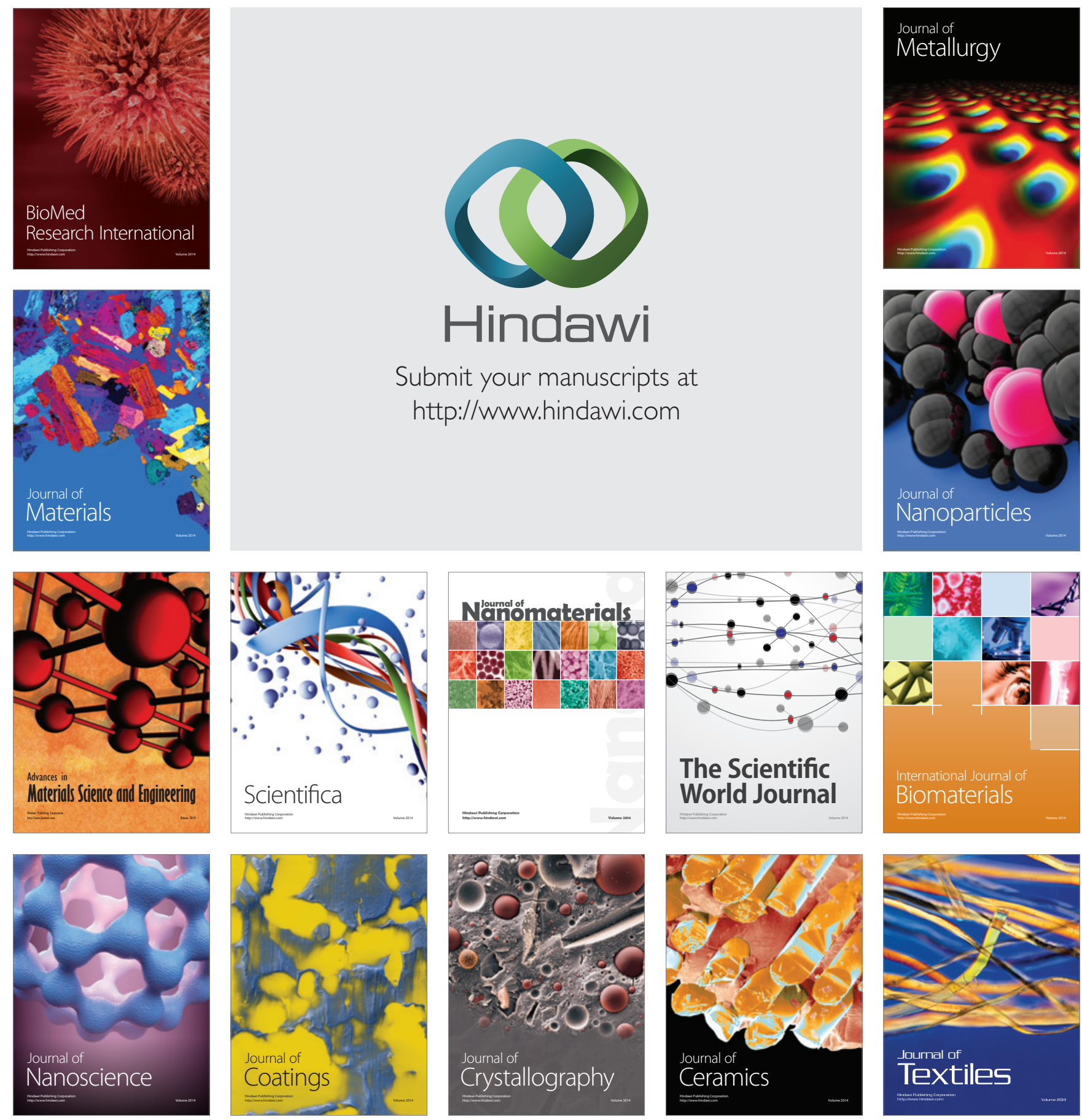